\title{
Development of 30 SNP Markers for the Daphnia Magna based on Restriction Site-associated DNA Sequencing (RAD-seq)
}

\section{Shengman Zhang}

Shanghai Ocean University

\section{Wenhui He}

Shanghai Ocean University

Haisu Zheng

Shanghai Ocean University

Yiran Xiong

Shanghai Ocean University

Meng Tan

Shanghai Ocean University

\section{Zheng Han}

Shanghai Ocean University

\section{Siwei Chen}

Shanghai Ocean University

Peimin He ( $\nabla$ pmhe@shou.edu.cn )

Shanghai Ocean University https://orcid.org/0000-0003-3704-7905

\section{Research Article}

Keywords: Daphnia magna, SNP markers, Genetic diversity analysis, RAD-seq

Posted Date: February 11th, 2021

DOI: https://doi.org/10.21203/rs.3.rs-162999/v1

License: (c) (1) This work is licensed under a Creative Commons Attribution 4.0 International License. Read Full License 


\title{
Development of 30 SNP markers for the Daphnia magna based on restriction site-associated DNA sequencing (RAD-seq)
}

\author{
Shengman Zhang ${ }^{1,2 *}$, Wenhui He ${ }^{1,2 *}$, Haisu Zheng ${ }^{1,2,3}$, Yiran Xiong ${ }^{1}$, Meng Tan ${ }^{1,2}$, Zheng Han ${ }^{1,2}$, Siwei Chen \\ 1,2 Peimin $\mathrm{He}^{1,2}$ \\ ${ }^{1}$ College of Marine Ecology and Environment, Shanghai Ocean University, Shanghai, China \\ ${ }^{2}$ Water Environment and Ecology Engineering Research Center of Shanghai Institution of Higher Education, \\ Shanghai, China \\ ${ }^{3}$ College of Fisheries and Life Sciencet, Shanghai Ocean University, Shanghai, China \\ Corresponding author Peimin He: pmhe@shou.edu.cn \\ * These authors have contributed equally to this work.
}

\begin{abstract}
:
Daphnia magna belongs to the Cladocera and plays an important role in the water ecosystem. With the intensification of water pollution, the wild population of $D$. magna has declined rapidly in recent years, and insufficient molecular markers have limited effective research and conservation of this species. In this research, 30 novel single nucleotide polymorphism (SNP) markers were developed in a cultivar of Daphnia magna and 12 wild Daphnia magna using restriction site-associated DNA sequencing (RAD-seq). The minor allele frequency, observed heterozygosity, and expected heterozygosity ranged from 0.115 to $0.721,0.073$ to 0.800 , and 0.077 to 0.520 , respectively. The PIC ranged from 0.071 to 0.403 . Six loci showed significant deviations from the Hardy-Weinberg equilibrium after Bonferroni correction $(\mathrm{p}<$ 0.05). These newly developed polymorphic SNP markers for D. magna are of great significance in terms of the genetic breeding of D. magna, identification of wild and artificially domesticated species and conservation genetics research.
\end{abstract}

\section{KEYWORDS:}

Daphnia magna; SNP markers; Genetic diversity analysis; RAD-seq 
Daphnia magna belongs to the Cladocera and is an important species of zooplankton (Jeong and Simpson 2019). It mainly lives in freshwater. Daphnia magna helps to increase the diversity of phytoplankton in the water body and build a stable phytoplankton community structure, as well preventing the occurrence of cyanobacteria blooms (Sarnelle 2007). It is the key to balance in the water ecosystem. In China, the artificially domesticated Daphnia magna has been used to inhibit Cyanobacteria blooms and restore submerged vegetation, which has been used in more than 400 ecological restoration projects (Huo et al. 2010; Peng et al. 2011). In addition, it is widely used in water pollution monitoring and aquatic organism toxicological research (Dietrich et al. 2010; Fan et al. 2011). However, in recent years, with the rapid expansion of the population and increases in the discharge of domestic sewage, the aquatic ecosystem has been severely damaged; relevant research shows that $54 \%$ of Asian, $53 \%$ of European, $48 \%$ of North American, $41 \%$ of South American, and $28 \%$ of African rivers are eutrophic water bodies, and eutrophication of water bodies is currently the most serious problem facing rivers and lakes (Bagousse et al. 2012), as a result, the habitat of D. magna has been severely damaged, and its genetic diversity is also declining sharply. To date, a comprehensive study of $D$. magna population genetic variations is still lacking, and very little information is available on the genome and effective molecular markers of $D$. magna. This hinders correlational studies on this species. Thus, it is very important to investigate the genetic diversity of this species for scientific management and sustainable utilization in the future.

Genetic methods based on DNA markers are extremely efficient at revealing population distributions and the laws of evolution (Hao et al. 2017; Chen et al. 2018; Zhao et al. 2019; Liu et al. 2020a; Liu et al. 2020b). Using genetic marker 
technologies, the differences and dynamics of populations can be understood. The disclosure of genetic diversity and genetic structure is also the basis of species genetic management (Manel et al. 2003; Schwartz et al. 2007). Because single nucleotide polymorphism (SNPs) are codominant, dimorphic, allelic, and widely distributed (Vignal et al. 2002; Céline et al. 2018; Honorio et al. 2019), they have become among the most advanced DNA markers. Nowadays, SNP have been widely used in genetic structure analysis, cultivar identification, genetic diversity evaluation, construction of high-density genetic linkage maps, and molecular-assisted breeding (Gupta et al. 2008; Pujolar et al. 2013; Vasemagi and Primmer 2005).

Restriction site-associated DNA sequencing (RAD-seq) is an important sequencing technology for simplifying the genome. It has a high number of markers and high density, and can be applied in many fields. For research subjects without a reference genome, RAD-seq technology is the best choice for simplifying genome establishment (Miller et al. 2007). This technology has been widely used in research in the fields of population genetics, genetic map construction, and systematic evolution ( $\mathrm{Li}$ et al. 2018). Here, we adopted restriction site-associated DNA (RAD-seq) technology (Miller et al. 2007) and reported on the development and verification of SNP markers in D. magna.

The experimental materials used in this research were taken from the breeding base of Shanghai Taihe Water Environment Technology Development Co., Ltd. (DZ), Yantai (YT), Jining (JN), Yunnan (YN), Hainan (HNa), Jiangsu (JS), Beijing (BJ), Hunan (HNb), Shanxi (SX), Liaoning (LN), Guangdong (GD), Anhui (AH), Sichuan (SC) (Table 1 and Figure 1). Hundreds of D. magna adult individuals were randomly collected from 12 wild population sampling sites and brought back to the laboratory for cultivation. The TIANGEN DP304 kit (TIANGEN BIOTECH Co., Ltd, China) was used to extract 50 asexual reproduction cultured adult D. magna genomic DNA samples, and the integrity was checked using $1.5 \%$ agarose gel electrophoresis. The purity and concentration of the DNA were detected using a UV spectrophotometer to ensure the genomic DNA obtained met the quality conditions for building a database. 
DNA samples were diluted to a concentration of $30 \mathrm{ng} / \mu \mathrm{L}$ and stored at $-20^{\circ} \mathrm{C}$ (Haier BCD-576WDPU, China).

Equal amounts of genomic DNA of D. magna were fused and Shanghai Map Biotech Co., Ltd. (Shanghai, China) performed RAD-seq to isolate and characterize SNP markers. The constructed RAD libraries were sequenced on the Illumina HiSeq 150 platform. After quality filtering, 19,631 putative SNPs with the highest scores were generated. Primer 3.0 software was used to develop SNP primers. A total of five samples, including YN, YT, JN, DZ, and JS were selected for verification using Sanger sequencing. Sequencing primer was general-purpose Common-F (AGTCACGACGTTGTAAAACGAC). We obtained preliminary polymorphic locus using Sanger sequencing, and then we used SNaPshot for group verification. After verification of the small group, the stability of the experimental system and process was confirmed. Following this, the remaining samples were verified by the large group. Allele frequency, observed heterozygosity $\left(\mathrm{H}_{\mathrm{O}}\right)$, and expected heterozygosity $\left(\mathrm{H}_{\mathrm{E}}\right)$ indices were calculated using GenAlEx 6.5 (Peakall and Smouse 2012). The polymorphism information content (PIC) and Hardy-Weinberg distribution (HWE) were estimated at the population level using Arlequin v3.0 (Chaves et al. 2018; Excoffier 2005). 


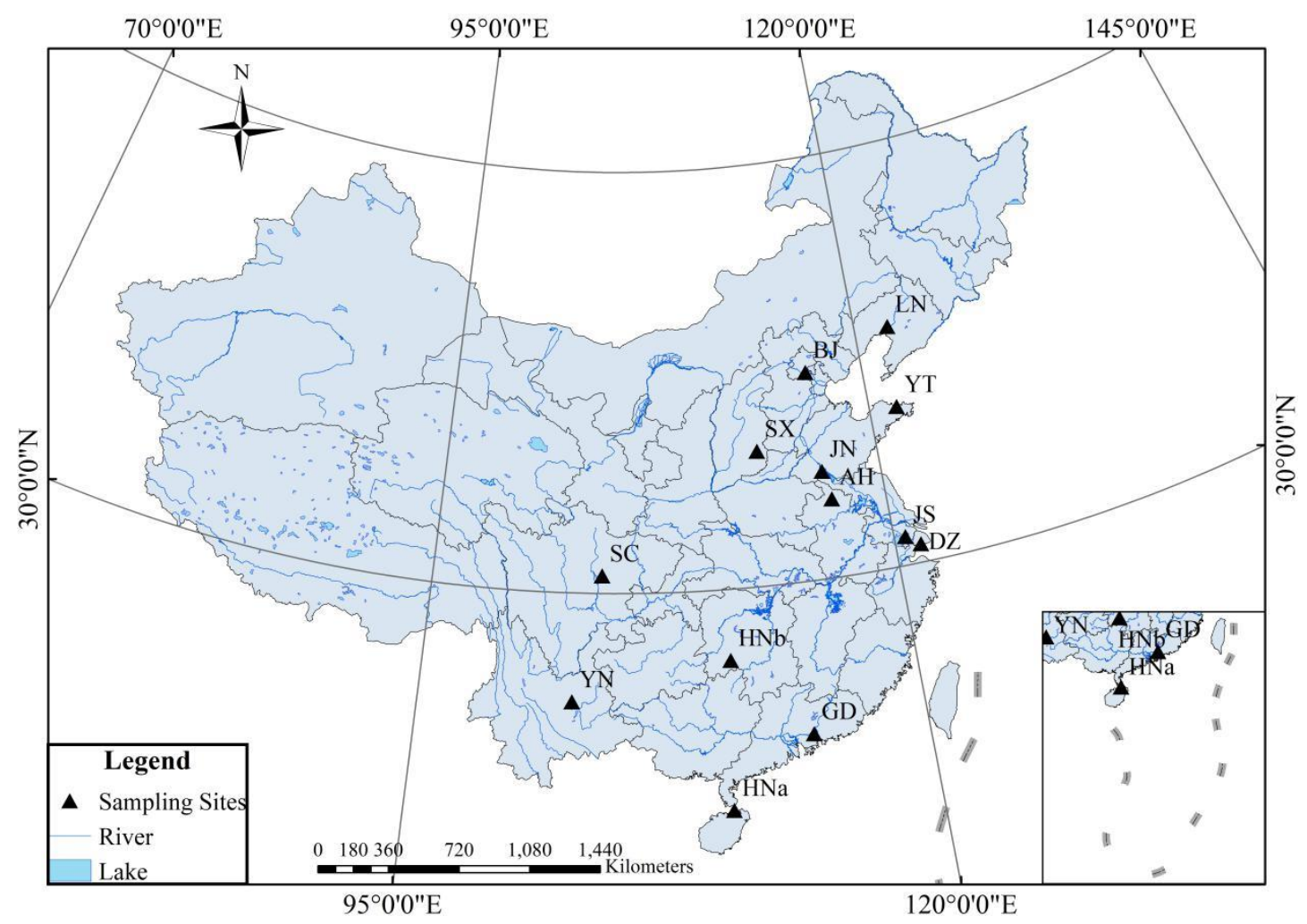

Figure 1 The map of the sampling locations of the 13 populations of Daphnia magna in the present study.

Table 1 Information on samples used for genetic marker development

\begin{tabular}{|c|c|c|c|c|}
\hline Sampling sites & Codes & Longitude & Latitude & Dates \\
\hline Taihe Water Co., Ltd. & $\mathrm{DZ}$ & $121^{\circ} 21^{\prime} 34.7 " \mathrm{E}$ & $30^{\circ} 50^{\prime} 50.9^{\prime \prime} \mathrm{N}$ & 2019.09 \\
\hline Yan tai & YT & $121^{\circ} 37^{\prime} 44.4^{\prime \prime E}$ & $37^{\circ} 23^{\prime} 33.6^{\prime \prime} \mathrm{N}$ & 2019.11 \\
\hline Ji ning & $\mathrm{JN}$ & $116^{\circ} 39^{\prime} 36.5^{\prime \prime} \mathrm{E}$ & $35^{\circ} 0^{\prime} 36.5^{\prime \prime} \mathrm{N}$ & 2019.11 \\
\hline Yun nan & YN & $102^{\circ} 39^{\prime} 41.7^{\prime \prime} \mathrm{E}$ & $25^{\circ} 1 ' 20.8^{\prime \prime} \mathrm{N}$ & 2019.12 \\
\hline Hai nan & $\mathrm{HNa}$ & $110^{\circ} 20^{\prime} 7.9^{\prime \prime} \mathrm{E}$ & $20^{\circ} 3^{\prime} 45.2^{\prime \prime} \mathrm{N}$ & 2019.12 \\
\hline
\end{tabular}




\begin{tabular}{|c|c|c|c|c|}
\hline Jiang su & JS & $120^{\circ} 36^{\prime} 37.8^{\prime \prime} \mathrm{E}$ & $31^{\circ} 19^{\prime} 18.1^{\prime \prime} \mathrm{N}$ & 2020.01 \\
\hline Bei jing & BJ & $116^{\circ} 32^{\prime} 27.2^{\prime \prime} \mathrm{E}$ & $39^{\circ} 46^{\prime} 7.9^{\prime \prime} \mathrm{N}$ & 2020.04 \\
\hline Hu nan & $\mathrm{HNb}$ & $110^{\circ} 39^{\prime} 59.2^{\prime \prime} \mathrm{E}$ & $26^{\circ} 45^{\prime} 1.9^{\prime \prime} \mathrm{N}$ & 2020.05 \\
\hline Shan xi & SX & $113^{\circ} 4^{\prime} 33.4^{\prime \prime} \mathrm{E}$ & $36^{\circ} 19^{\prime} 56.0^{\prime \prime} \mathrm{N}$ & 2020.06 \\
\hline Liao ning & $\mathrm{LN}$ & $122^{\circ} 6^{\prime} 44.9^{\prime \prime} \mathrm{E}$ & $41^{\circ} 12^{\prime} 51.9^{\prime \prime} \mathrm{N}$ & 2020.06 \\
\hline Guang dong & GD & $114^{\circ} 25^{\prime} 17.7^{\prime \prime} \mathrm{E}$ & $23^{\circ} 6^{\prime} 7.3^{\prime \prime} \mathrm{N}$ & 2020.06 \\
\hline An hui & $\mathrm{AH}$ & $116^{\circ} 58^{\prime} 50.9^{\prime \prime} \mathrm{E}$ & $33^{\circ} 39^{\prime} 21.4^{\prime \prime} \mathrm{N}$ & 2020.07 \\
\hline Si chuan & $\mathrm{SC}$ & $104^{\circ} 4^{\prime} 58.8^{\prime \prime} \mathrm{E}$ & $30^{\circ} 48^{\prime} 52.5^{\prime \prime} \mathrm{N}$ & 2020.07 \\
\hline
\end{tabular}

A total of 30 SNP loci were polymorphic. The name of the SNP locus, primer sequences (5'-3'), SNP type, fragment size, Minor allele frequency (MAF), observed heterozygosities $\left(H_{O}\right)$, expected heterozygosities $\left(H_{E}\right)$ polymorphic information content (PIC) and probability for Hardy-Weinberg equilibrium tests (HWEP) were shown in Table 2. Minor allele frequency (MAF) varied from 0.115 to 0.721 , the mean MAF was 0.311. The observed heterozygosity $\left(H_{O}\right)$ ranged from 0.073-0.800, and the mean $H_{O}$ was 0.262 . The expected heterozygosity $\left(H_{E}\right)$ was between 0.077-0.520, and the mean $\mathrm{H}_{\mathrm{E}}$ was 0.330 . The Polymorphic information content (PIC) range was $0.071-0.403$, with an average of 0.270 . Across all samples, 6 of 30 loci showed significant deviations from HWEP after Bonferroni correction $(\mathrm{p}<0.05)$, but no significant linkage disequilibrium was found. The results showed that 13 D. magna populations had good genetic polymorphism.

Table 2 Characterization of 30 SNPs in Daphnia magna 


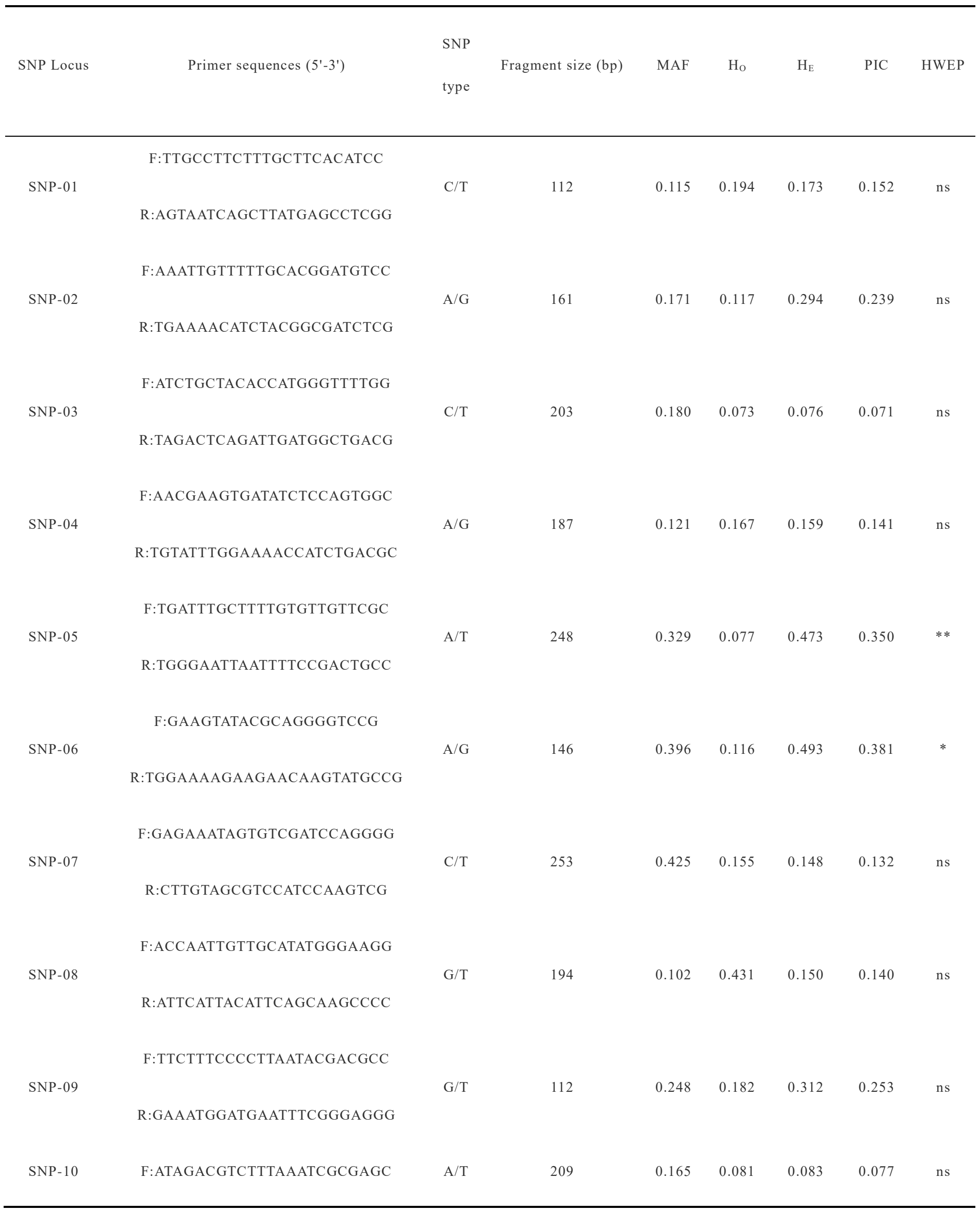


R:CTGGCGTCAATTCAACTTGTAGC

F:GCCGTGTATACTTTCTGATTAGCC

SNP-11

R:CCAAAAGTTCGCAAGGTTCTACC

F:GTCATAGCCAACTTGTAACGTGG

SNP-12

R:AAGCACAATGCCAAGAATAACCG

F:AAAAGTTTCCATGACTTCAGCCC

SNP-13

R:AACGTTTCATTCTACAATTCAAACAGG

F:AATTCAACGTTCCCACTTTGCG

SNP-14

R:CAATGGCTTCCCGTGTTTAATGG

F:ATCATGTGGGTTACTGTGAGACC

SNP-15

R:GGGTATCTTTCAAAAGCATCCGG

F:GCATTGGCCCTCTACTTTTATGC

SNP-16

R:GTAACAGCGCAAATGATTTGAGG

F:TCTGGTTCGACATTTCTTTTTCGG

SNP-17

R:CTAGATTTTCTACGACAGTCGAGC

F:GAACTGATTGGCCAGAACAAGC

SNP-18

R:CTTTGCCCATCAGCTCAATGC

F:CACGGTGCTAATAATCTACGTCG

SNP-19

R:CGATGTAGTCTGGTTGTGAGAGG

F:TTTTCGTCCCTTATCTTGACCCC

SNP-20

R:CGGTGCAAAACATACTGTTACCC

SNP-21

R:CGGTGCAAAACATACTGTTACCC

F:TGTTTTGTCAATGCTTAAGGGCG
$\mathrm{C} / \mathrm{T}$

187

$0.200 \quad 0.100$

0.100

0.090

ns

A/G

227

0.431

0.727

0.520

0.393

ns

A/G

322

$0.449 \quad 0.093$

0.507

0.387

A/C

210

0.2

0.462

0.369

0.292

ns

$\mathrm{A} / \mathrm{C}$

176

0.177

0.308

0.271

0.226

ns

A/T

271

0.308

0.250

0.475

0.375

ns

G/C

211

0.384

0.396

0.437

0.371

ns

G/C

251

0.3

0.231

0.409

0.316

ns

C/T

208

0.244

0.078

0.471

0.350

212

$0.136 \quad 0.091$

0.091

0.083

ns

$\mathrm{C} / \mathrm{T}$

230

0.721

0.154

0.492

0.381 


\section{F:TTCCTTTTGCAACACTTCGTTCG}

SNP-22

R:CGGAATGAAGGTCGACCAGC

F:TTGGGAGTAAACCAGCAATTAGC

SNP-23

R:TATCGGGCGATTGAAAAACTGC

F:CTCTTGTCCCACTTATGCCTTCC

SNP-24

R:CACCCTACAGCAAAGACTAGAGC

F:TAATTAGGCGCGTCATCAAAACG

SNP-26

R:GAAGGGGAGTAATTCACGCTACG

F:TCGGTGAAATATCGAATGATGTGC

SNP-26

R:ATGAAGACAAATCCAACAGTCGG

F:GATGCCACATTTTTCAAACCAGG

SNP-27

R:TCCTCACTATTCGATCAGACAACG

F:GCTCCTAAATTGGCTTGATGACG

SNP-28

R:CTCTAAGAAAGGCCCTCTTCAGG

F:TTCGGAACTTTTGTTTCCCATCC

SNP-29

R:CCGCTGCCAGATTAAATCTAACG

F:TGGCAAATTTAACAGGTGCTACG

SNP-30
$\mathrm{C} / \mathrm{T}$

145

$0.254 \quad 0.231$

0.323

0.262

ns

G/T

189

0.426

0.077

0.409

0.316

$\mathrm{A} / \mathrm{T}$

197

0.467

0.500

0.479

0.372

ns

$\mathrm{A} / \mathrm{T} \quad 201$

0.355

0.455

0.507

0.387

ns

C/T

154

0.308

0.229

0.327

0.202

ns

A/G

246

0.332

0.426

0.441

0.403

ns

$\mathrm{A} / \mathrm{T}$

208

0.551

0.464

0.321

0.388

ns

C/T

185

0.086

0.189

0.086

0.177

ns

\section{R:TATCGGTCAATCCAGCAATCAGG}

MAF: Minor allele frequency; PIC: Polymorphism information content; $H_{E}$ : Expected heterozygosity; $H_{O}$ : Observed heterozygosity; HWEP: probability for Hardy-Weinberg equilibrium tests, ns non-significant, ${ }^{*} \mathrm{P}<0.05,{ }^{* *} \mathrm{P}<0.01,{ }^{* * *} \mathrm{P}<$ 0.001 . 
To our knowledge, this is the first time SNP markers were developed for $D$. magna, thus, filling the gap in the field. The application of RAD-seq technology is continuously expanding, and it has been widely used for gene mapping (Guo et al. 2015), high-precision genetic map construction (Zhang et al. 2018) and assessments of genetic diversity (Pootakham et al. 2011). Our study identified 30 polymorphic SNP markers using RAD-seq, which can efficiently and accurately identify the $D$. magna populations in different geographic regions, thereby revealing the genetic structure of D. magna populations and providing molecular marker reference for subsequent research on D. magna. Our research results are of great significance for identification of wild and artificially domesticated species, genetic breeding, evaluation of genetic diversity, genetic relationship identification, construction of a genetic map, and protection of germplasm resources of this species.

\section{Acknowledgements}

We wish to thank Shanghai Taihe Water Environment Technology Development Co., Ltd for help with experimental materials. We wish to thank Shanghai Map Biotech Co., Ltd. for RAD sequencing. We declare that there is no apparent or potential conflict of interest in the authors' report. SMZ and WHH have contributed equally to this work. In addition, people who participated in the experiment and writing work of this paper are included in the authors.

\section{Author contributions}

PMH designed the study and wrote the final draft of the manuscript. SMZ did all the practical work and data analyses and wrote the first version of the manuscript, WHH assisted in discussions and revisions of the manuscript. All authors contributed to writing.

\section{Funding}

This work was supported by National Water Pollution Control and Treatment Science and Technology Major Project of China [2017ZX07205]. 


\section{Data availability}

Provided as supporting information.

\section{Compliance with ethical standards}

Conflict of interest The authors declare no competing interest in this work.

Ethical approval Samples were caught from wild water bodies and provided by Shanghai Taihe Water Environment Technology Development Co.,Ltd, and no specific permissions were required. All experiments were conducted after review and approval from the local Ethical Committee.

\section{References}

Bagousse YL, Liancourt P, Gross N, Straile D (2012) Indirect facilitation promotes macrophyte survival and growth in freshwater ecosystems threatened by eutrophication. J Ecol 100:530538.

Céline BJ, Kersten B, Bourland N, Erwan G, Adline D, Jean LD, Bernd D (2018) Development of nuclear SNP markers for the timber tracking of the African tree species Sapelli, Entandrophragma cylindricum. Conserv Genet Resour.

Chaves CL, Blanc JC, Sebbenn AM, Malte M, Barbara RV, Meyer S, Kathelyn PV, Euridice N, Honorio C, Carmen GD, Niklas T, Valerie T, Marie M, Bernd D (2018) Nuclear and chloroplastic SNP markers for genetic studies of timber origin for Hymenaea trees. Conserv Genet Resour.

Chen LP, Chang YG, Li J, Wang JM, Liu JL, Zhi YC, Li XJ (2018) Application of DNA barcoding in the classifcation of grasshoppers (Orthoptera: Acridoidea) - a case study of grasshoppers from Hebei Province, China. Zootaxa 4497(1):99-110.

Dietrich S, Ploessl F, Bracher F, Laforsch C (2010) Single and combined toxicity of pharmaceuticals at environmentally relevant concentrations in Daphnia magna--a multigenerational study. Chemosphere 79:60-66. 
Excoffier L (2005) Arlequin (version 3.0): an integrated software package for population genetics data analysis. Evol Bioinform.

Fan WH, Wu CG, Zhao CM, Yu T, Zhang Y (2011) Application of enriched stable isotope technique to the study of copper bioavailability in Daphnia magna. J Environ Sci $23: 831-836$

Guo F, Yu HW, Tang Z, Jiang XL, Wang L, Wang X, Xu Q, Deng XX (2015) Construction of a SNP-based high-density genetic map for pummelo using RAD sequencing. Tree Genet Genome 11(1):2.

Gupta PK, Rustgi S, Mir RR (2008) Array-based high-throughput DNA markers for crop improvement. Heredity, 101(1):5-18.

Hao JF, Zhang XH, Wang YS, Liu JL, Zhi YC, Li XJ (2017) Diversity investigation and application of DNA barcoding of Acridoidea from Baiyangdian Wetland. Biodiversity Science 25(4):409-417.

Honorio C, Eurídice N, Blanc J, Céline MM, Carmen R, García D, Alexandre M, Sebbenn BRV, Meyer S, Kathelyn PV, Niklas T, Valerie T, Marie M, Bernd D (2019) Development of nuclear and plastid SNP markers for genetic studies of Dipteryx tree species in Amazonia. Conserv Genet Resour.

Huo YZ, He WH, Luo K, Wang YY, Zhang YJ, Tian QT, He PM (2010) Bioremediation efficiency of applying Daphnia magna and submerged plants: a case study in Dishui Lake of Shanghai, China. Chinese J of Appl Ecol 21:495-499.

Jeong TY, Simpson MJ (2019) Daphnia magna metabolic profiling as a promising water quality parameter for the biological early warning system. Water Res, 166, 115033

Li B, Liu CL, Liu G, Chen SQ, Zhang LL, Ge JL, Li FH, Tan J (2018) SNP discovery in spotted halibut (Verasper variegatus) using restriction site-associated DNA sequencing (RAD-seq). Conserv Genet Resour 10:409. 
Liu JL, Zhao XH, Kang XY, Zhuang MM, Ding XW, Zhao LJ, Wen QL, Zhu Y, Gu K, Bao QJ, Yang XQ, Zhang JH, He PM (2020a) Good news: we can identify Ulva species erupted in the Yellow Sea more easily and cheaply now. Conserv Genet Resour 12(3):447-449.

Liu JL, Zhuang MM, Zhao LJ, Liu YK, Wen QL, Fu ML, Yu KF, Zhang JH, He PM (2020b) Taxonomy and genetic diversity of amphipods living on Ulva lactuca L. in Gouqi coast of China. Pac Sci 74(2):1-10.

Manel S, Schwartz MK, Luikart G, Taberlet P (2003) Landscape genetics:combining landscape ecology and population genetics. Trends Ecol Evol 18(4):189-197.

Miller MR, Dunham JP, Amores A, Cresko WA, Johnson EA (2007) Rapid and cost-effective polymorphism identification and genotyping using restriction site associated DNA (RAD) markers. Genome Res 17(2):240-248.

Miner BE, Knapp RA, Colbourne JK, Pfrender ME (2013) Evolutionary history of alpine and subalpine Daphnia in western North America. Freshwater Biol 58:1512-1522.

Peakall R, Smouse PE (2012) GenAlEx 6.5: genetic analysis in Excel. Population genetic software for teaching and research-an update. Bioinformatics 28:2537-2539.

Peng ZR, He W H, Gao JH, Yu YN (2011) Change of water quality during the ecological restoration in the Garden of Yuanmingyuan. J Shanghai Ocean Uni 20:457-461.

Pootakham W, Chanprasert J, Jomchai N, Sangsrakru D, Yoocha T, Therawattanasuk, K, Tangphatsornruang S (2011) Single nucleotide polymorphism marker development in the rubber tree, hevea brasiliensis (euphorbiaceae). Am J Bot 98(11):e337-e338.

Pujolar JM, Jacobsen MW, Frydenberg J, Als TD, Larsen PF, Maes GE, Zane L, Jian JB, Cheng L, Hansen MM (2013) A resource of genome-wide single-nucleotide polymorphisms generated by RAD tag sequencing in the critically endangered European eel. Mol Ecol Resour, 2013, $13: 706-714$

Sarnelle O (2007) Initial conditions mediate the interaction between Daphnia and bloom-forming cyanobacteria. Limnol Oceanogr 52:2120-2127. 
Schwartz MK, Luikart G, Waples RS (2007) Genetic monitoring as a promising tool for conservation and management. Trends Ecol Evol 22(1):25-33.

Vasemagi A, Primmer CR (2010) Challenges for identifying functionally important genetic variation: the promise of combining complementary research strategies. Mol Ecol, 14(12):3623-3642.

Vignal A, Milan D, SanCristobal M, Eggen A (2002) A review on SNP and other types of molecular markers and their use in animal genetics. Genet Sel Evol 34(3):275-305.

Zhang DF, Xia T, Dang SF, Fan GH, Wang ZL (2018) Investigation of Chinese Wolfberry (Lycium spp.) Germplasm by Restriction Site-Associated DNA Sequencing (RAD-seq). Biochem Genet 56(6):575-585.

Zhao XH, Cui JJ, Zhang JH, Shi JT, Kang XY, Liu JL, Wen QL, He PM (2019) Reproductive strategy of the floating alga Ulva prolifera in blooms in the Yellow Sea based on a combination of zoid and chromosome analysis. Mar Pollut Bull 146:584-590. 


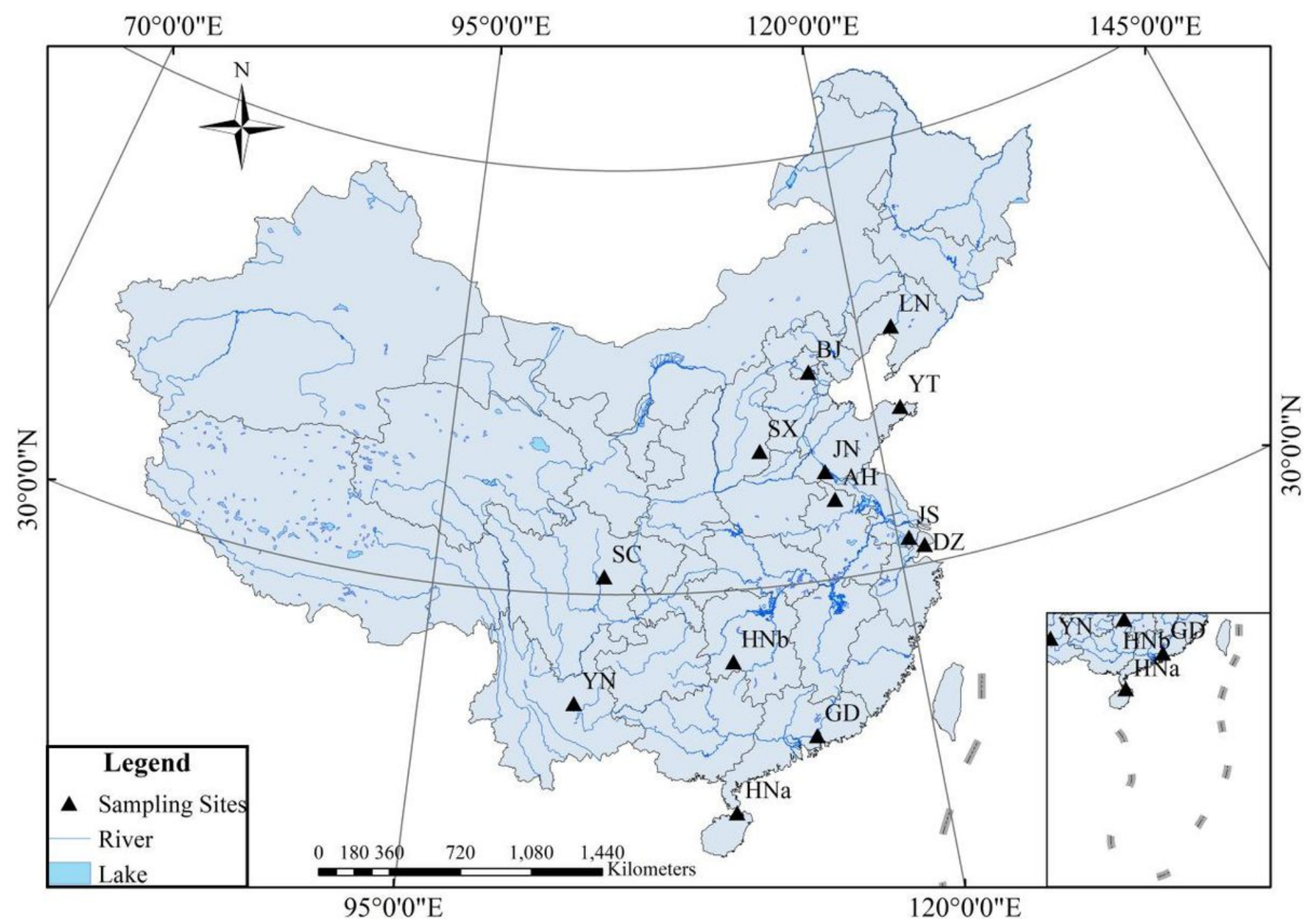

\section{Figure 1}

The map of the sampling locations of the 13 populations of Daphnia magna in the present study. Note: The designations employed and the presentation of the material on this map do not imply the expression of any opinion whatsoever on the part of Research Square concerning the legal status of any country, territory, city or area or of its authorities, or concerning the delimitation of its frontiers or boundaries. This map has been provided by the authors. 